CUBO A Mathematical Journal

Vol.20, $N^{\underline{O}_{3}}$, (65-79). October 2018

\title{
Ball comparison between Jarratt's and other fourth order method for solving equations
}

\author{
IoAnnis K. Argyros ${ }^{1}$ and Santhosh George ${ }^{2}$ \\ ${ }^{1}$ Department of Mathematical Sciences, \\ Cameron University, \\ Lawton, OK 73505, USA. \\ ${ }^{2}$ Department of Mathematical and Computational Sciences, \\ National Institute of Technology Karnataka, \\ India-575 025. \\ iargyros@cameron.edu, sgeorge@nitk.edu.in
}

\begin{abstract}
The convergence order of iterative methods is determined using high order derivatives and Taylor series, and without providing computable error bounds, uniqueness of the solution results or information on how to choose the initial point. We address all these problems by using hypotheses only on the first derivative. Moreover, to achieve all these we present our technique using a comparison between the convergence radii of Jarratt's fourth order method and another method of the same convergence order.
\end{abstract}

\section{RESUMEN}

El orden de convergencia de métodos iterativos es determinado usando derivadas de orden alto y series de Taylor, y sin poder entregar cotas de error calculables, resultados de unicidad de soluciones o información de cómo elegir el punto inicial. Tratamos estos problemas usando hipótesis sólo en la primera derivada. Más aún, para responder todos los anteriores, presentamos una técnica que usa una comparación entre el radio de convergencia del método de cuarto orden de Jarratt y otro método con el mismo orden de convergencia.

Keywords and Phrases: Jarratt method; Banach space; Ball convergence.

2010 AMS Mathematics Subject Classification: 65D10, 65D99. 


\section{Introduction}

Let $\mathcal{B}_{1}$ and $\mathcal{B}_{2}$ stand for Banach spaces, with $\Omega \subseteq \mathcal{B}_{1}$ being nonempty, open and convex. Consider an equation

$$
\mathrm{F}(\mathrm{x})=0
$$

where $F: \Omega \longrightarrow \mathcal{B}_{2}$ is a differentiable in the of Fréchet-sense. The task of finding a solution $p$ of equation (1.1) is very difficult in general. It is even harder to find a solution $p$ in closed form, since this can be achieved in some special cases. That explains why most authors develop iterative methods, to generate a sequence approximating $p$ under some initial conditions.

Notice that, solution methods for equation (1.1) is an important area of research, since a plethora of problems from diverse disciplines such that Mathematics, Optimization, Mathematical Programming, Chemistry, Biology, Physics, Economics, Statistics, Engineering and other disciplines can be modeled into an equation of the form (1.1) using mathematical modeling [1, 2, 3, 4, 5, 6, 7, 8, 9, 10, 11, 12, 13, 14, 15, 16. The most popular method is without a doubt Newton's method (NM)

$$
x_{n+1}=x_{n}-F^{\prime}\left(x_{n}\right)^{-1} F\left(x_{n}\right), x_{0} \in \Omega, \text { and all } n=0,1,2, \ldots
$$

NM converges quadratically to $p$ for $x_{0}$ sufficiently close to $p$ [10]. To increase the convergence order numerous methods have been proposed [1, 2, 3, 4, 5, 6, 7, 8, 9, 10, 11, 12, 13, 14, 15, 16]. The order of these methods is almost exclusively been obtained using Taylor series, and hypotheses on high order derivatives. No computable error bounds or uniqueness results are given, and the choice of the initial point is a shot in the dark.

Iterative methods are usually studied based on: semi-local and local convergence. The semilocal convergence matter is, based on the information around an initial point, to give conditions ensuring the convergence of the iterative procedure; while the local one is, based on the information around a solution, to find estimates of the radii of convergence balls $1,2,2,4,4,5,6,7,8,9,10,11$, 12, 13, 14, 15, 16.

A radius of convergence about $p$ determines a ball such that if an initial point is selected from that ball convergence of the method to $p$ is guaranteed. To deal with all these problems we have selected two popular fourth order methods. In particular, we compare the radii of convergence of fourth order Jarratt's iterative method defined [9, 12] for $n=0,1,2, \ldots$, as

$$
\begin{aligned}
y_{n}= & x_{n}-\frac{2}{3} F^{\prime}\left(x_{n}\right)^{-1} F\left(x_{n}\right) \\
x_{n+1}= & x_{n}-\frac{1}{2}\left[\left(3 F^{\prime}\left(y_{n}\right)-F^{\prime}\left(x_{n}\right)\right)^{-1}\left(3 F^{\prime}\left(y_{n}\right)+F^{\prime}\left(x_{n}\right)\right)\right] \\
& \times F^{\prime}\left(x_{n}\right)^{-1} F\left(x_{n}\right),
\end{aligned}
$$


to the fourth order Sharma's method [13] defined for $n=0,1,2, \ldots$, as

$$
\begin{aligned}
y_{n}= & x_{n}-\frac{2}{3} F^{\prime}\left(x_{n}\right)^{-1} F\left(x_{n}\right) \\
x_{n+1}= & x_{n}-\frac{1}{2}\left[-I+\frac{9}{4} F^{\prime}\left(y_{n}\right)^{-1} F^{\prime}\left(x_{n}\right)+\frac{3}{4} F^{\prime}\left(x_{n}\right)^{-1} F^{\prime}\left(y_{n}\right)\right] \\
& \times F^{\prime}\left(x_{n}\right)^{-1} F\left(x_{n}\right) .
\end{aligned}
$$

Earlier convergence analysis of these methods, in the special case when $\mathcal{B}_{1}=\mathcal{B}_{2}=\mathbb{R}^{\mathrm{k}}$ used, assumptions of the Fréchet derivatives of $F$ of order up to five [9, 12, 13]. But these assumptions limit the applicability of methods (1.3) and (1.4).

Let as an example, $\mathcal{B}_{1}=\mathcal{B}_{2}=\mathbb{R}, \Omega=\left[-\frac{1}{2}, \frac{3}{2}\right]$. Define $\mathrm{F}$ on $\Omega$ as

$$
F(x)=x^{3} \log x^{2}+x^{5}-x^{4}
$$

Then, we have $p=1$, and

$$
\begin{gathered}
F^{\prime}(x)=3 x^{2} \log x^{2}+5 x^{4}-4 x^{3}+2 x^{2}, \\
F^{\prime \prime}(x)=6 x \log x^{2}+20 x^{3}-12 x^{2}+10 x, \\
F^{\prime \prime \prime}(x)=6 \log x^{2}+60 x^{2}=24 x+22 .
\end{gathered}
$$

Clearly, $F^{\prime \prime \prime}(x)$ is not bounded on $\Omega$. So, methods (1.3) and (1.4) cannot be applied to solve the above example, if we use the analysis in the earlier studies. In this study, our analysis uses only the assumptions on the first Fréchet derivative of $F$.

Moreover, we provide computable upper estimates on $\left\|x_{n}-p\right\|$, a radius of convergence as well as uniqueness results based on generalized Lipschitz conditions. Hence, we extend the applicability of these methods. Our technique can be used to extend the applicability of other high order methods along the same lines.

The rest of the study is organized as follows. In Section 2 , the local convergence analysis is given and numerical examples are given in the last Section 4.

\section{Local convergence}

It is convenient for the local convergence analysis of method (1.3) and method (1.4) to introduce some fucntions and parameters. First for method (1.3): Let $\omega_{0}: S \longrightarrow S$ be a continuous and increasing function with $w_{0}(0)=0$, where $S=[0, \infty)$. Suppose that equation

$$
\omega_{0}(t)=1
$$

has at least one positive solution. Denote by $\rho_{0}$ the smallest such solution. Set $S_{0}=\left[0, \rho_{0}\right)$. Let also $\omega: S_{0} \longrightarrow S$ and $\omega_{1}: S_{0} \longrightarrow S$ be continuous and increasing functions with $\omega(0)=0$. Define 
functions $\varphi_{1}$ and $\bar{\varphi}_{1}$ on the interval $S_{0}$ by

$$
\varphi_{1}(t)=\frac{\int_{0}^{1} \omega((1-\theta) t) d \theta+\frac{1}{3} \int_{0}^{1} \omega_{1}(\theta t) d \theta}{1-\omega_{0}(t)}
$$

and

$$
\bar{\varphi}_{1}(\mathrm{t})=\varphi_{1}(\mathrm{t})-1 .
$$

Suppose that

$$
\omega_{0}(0)<3 \text {. }
$$

Then, we get by (2.2) that $\bar{\varphi}_{1}(0)<0$ and $\bar{\varphi}_{1}(\mathrm{t}) \longrightarrow \infty$ as $\mathrm{t} \longrightarrow \rho_{0}^{-}$. The intermediate value theorem guarantees that equation $\bar{\varphi}_{1}(t)=0$ has at least one solution in $\left(0, \rho_{0}\right)$. Denote by $R_{1}$ the smallest such solution. Suppose that equation

$$
\omega_{0}\left(\varphi_{1}(t) t\right)=1
$$

has at least one positive solution. Denote by $\rho_{1}$ the smallest such solution. Set $\rho=\min \left\{\rho_{0}, \rho_{1}\right\}$ and $S_{1}=[0, \rho)$. Define functions $\varphi_{2}$ and $\bar{\varphi}_{2}$ on $S_{1}$ by

$$
\begin{aligned}
\varphi_{2}(t)= & \frac{\int_{0}^{1} \omega((1-\theta) t) d \theta}{1-\omega_{0}(t)}+\frac{3}{8}\left[\frac{\left(\omega_{0}\left(\varphi_{1}(t) t\right)+\omega_{0}(t)\right)^{2}}{\left(1-\omega_{0}(t)\right)\left(1-\omega_{0}\left(\varphi_{1}(t) t\right)\right)}\right. \\
& \left.+2 \frac{w_{0}\left(\varphi_{1}(t) t\right)+\omega_{0}(t)}{1-\omega_{0}\left(\varphi_{1}(t) t\right)}\right] \frac{\int_{0}^{1} \omega_{1}(\theta t) d \theta}{1-\omega_{0}(t)}
\end{aligned}
$$

and

$$
\bar{\varphi}_{2}(\mathrm{t})=\varphi_{2}(\mathrm{t})-1
$$

We get that $\bar{\varphi}_{2}(0)=-1$ and $\bar{\varphi}_{2}(t) \longrightarrow \infty$ as $t \longrightarrow \rho^{-}$. Denote by $R_{2}$ the smallest such solution of equation $\bar{\varphi}_{2}(t)=0$. Moreover, define a radius of convergence $R$ by

$$
R=\min \left\{R_{1}, R_{2}\right\}
$$

It follows that for each $t \in[0, R)$

$$
\begin{gathered}
0 \leq \omega_{0}(t)<1 \\
0 \leq \omega_{0}\left(\varphi_{1}(t) t\right)<1 \\
0 \leq \varphi_{1}(t)<1
\end{gathered}
$$

and

$$
0 \leq \varphi_{2}(\mathrm{t})<1
$$

Let us introduce conditions (A):

(a1) $F: \Omega \longrightarrow \mathcal{B}_{2}$ is continuously differentiable in the sense of Fréchet and there exists $p \in \Omega$ such that $F(p)=0$ and $F^{\prime}(p)^{-1} \in \mathcal{L}\left(\mathcal{B}_{2}, \mathcal{B}_{1}\right)$. 
(a2) There exists function $\omega_{0}: S \longrightarrow S$ continuous and increasing with $\omega_{0}(0)=0$ and for each $x \in \Omega$

$$
\left\|F^{\prime}(p)^{-1}\left(F^{\prime}(x)-F^{\prime}(p)\right)\right\| \leq \omega_{0}(\|x-p\|)
$$

and (2.2) holds. Set $\Omega_{0}=\Omega \cap \mathrm{U}\left(\mathrm{p}, \rho_{0}\right)$, where $\rho_{0}$ is given in (2.1).

(a3) There exist functions $\omega: S_{0} \longrightarrow S, \omega_{1}: S_{0} \longrightarrow S$ continuous and increasing with $\omega(0)=0$ such that for each $x, y \in \Omega_{0}$

$$
\left\|F^{\prime}(p)^{-1}\left(F^{\prime}(y)-F^{\prime}(x)\right)\right\| \leq w(\|y-x\|)
$$

and

$$
\left\|F^{\prime}(p)^{-1} F^{\prime}(x)\right\| \leq \omega_{1}(\|x-p\|) .
$$

(a4) $\overline{\mathrm{U}}(\mathrm{p}, \mathrm{R}) \subset \Omega, \rho_{0}, \rho_{1}$ exist and are given by (2.1) and (2.3), respectively.

(a5) There exists $R^{*} \geq R$ such that

$$
\int_{0}^{1} \omega_{0}\left(\theta R^{*}\right) d \theta<1
$$

Set $\Omega_{1}=\Omega \cap \overline{\mathrm{U}}\left(\mathrm{p}, \mathrm{R}^{*}\right)$.

Next, the local convergence analysis is given for method (1.3) based on the conditions (A) and the preceding notation.

Theorem 2.1. Suppose that the conditions (A) hold. Then, sequence $\left\{x_{n}\right\}$ generated by (1.3), starting at $\mathrm{x}_{0} \in \mathrm{U}(\mathrm{p}, \mathrm{R})-\{\mathrm{p}\}$ is well defined, remains in $\mathrm{U}(\mathrm{p}, \mathrm{R})$ for each $\mathrm{n}=0,1,2,3, \ldots$ and converges to $\mathrm{p}$. Moreover, the following error bounds hold

$$
\left\|y_{n}-p\right\| \leq \varphi_{1}(\|x-p\|)\|x-p\| \leq\|x-p\|<R
$$

and

$$
\left\|x_{n+1}-p\right\| \leq \varphi_{2}(\|x-p\|)\|x-p\| \leq\|x-p\|,
$$

where functions $\varphi_{1}$ and $\varphi_{2}$ are given previously and $\mathrm{R}$ is defined in 2.4). Furthermore, the limit point $\mathrm{p}$ is the only solution of equation $\mathrm{F}(\mathrm{x})=0$ in the set $\Omega_{1}$, which is defined in (a5).

Proof. Mathematical induction is utilized to show (2.9) and (2.10). Let $x \in U(p, R)-\{p\}$. Then, by (a1), (a2), (2.1), (2.4) and (2.5), we obtain in turn that

$$
\left\|F^{\prime}(p)^{-1}\left(F^{\prime}(x)-F^{\prime}(p)\right)\right\| \leq \omega_{0}(\|x-p\|) \leq \omega_{0}(R)<1 .
$$

In view of (2.11) and the Banach lemma on invertible operators [7, $8,10, F^{\prime}(x)^{-1} \in \mathcal{L}\left(\mathcal{B}_{2}, \mathcal{B}_{1}\right)$ and

$$
\left\|F^{\prime}(x)^{-1} F^{\prime}(p)\right\| \leq \frac{1}{1-w(\|x-p\|)} .
$$


The point $y_{0}$ is well defined by the first substep of method (1.3) and (2.12) for $x=x_{0}$. We can write by (a1)

$$
F(x)=F(x)-F(p)=\int_{0}^{1} F^{\prime}(p+\theta(x-p))(x-p) d \theta .
$$

Then, by the second hypothesis in (a3), we get by (2.13) that

$$
\left\|F^{\prime}(p)^{-1} F^{\prime}(p)\right\| \leq \int_{0}^{1} \omega_{1}(\theta\|x-p\|) d \theta\|x-p\| .
$$

Using the first substep of method (1.3) for $n=0$, (a3), (2.4), (2.7), (2.12) (for $\left.x=x_{0}\right)$ and (2.14), we have in turn from

$$
y_{0}-p=x_{0}-p-F^{\prime}\left(x_{0}\right)^{-1} F\left(x_{0}\right)+\frac{1}{3} F^{\prime}\left(x_{0}\right)^{-1} F\left(x_{0}\right)
$$

that

$$
\begin{aligned}
\left\|y_{0}-p\right\| \leq & \left\|F^{\prime}\left(x_{0}\right)^{-1} F^{\prime}(p)\right\|\left\|\int_{0}^{1} F^{\prime}(p)^{-1}\left(F^{\prime}\left(p+\theta\left(x_{0}-p\right)\right)-F^{\prime}\left(x_{0}\right)\right) d \theta(x-p)\right\| \\
& \frac{1}{3}\left\|F^{\prime}\left(x_{0}\right)^{-1} F^{\prime}(p)\right\|\left\|F^{\prime}(p)^{-1} F\left(x_{0}\right)\right\| \\
\leq & \frac{\left[\int_{0}^{1} \omega\left((1-\theta)\left\|x_{0}-p\right\|\right) d \theta+\frac{1}{3} \int_{0}^{1} \omega_{1}\left(\theta\left\|x_{0}-p\right\|\right) d \theta\right]}{1-\omega_{0}\left(\left\|x_{0}-p\right\|\right)} \\
& \times\left\|x_{0}-p\right\| \\
= & \varphi_{1}\left(\left\|x_{0}-p\right\|\right)\left\|x_{0}-p\right\| \leq\left\|x_{0}-p\right\|<R,
\end{aligned}
$$

which implies that (2.9) holds for $n=0$ and $y_{0} \in U(p, R)$. Moreover, $F^{\prime}\left(y_{0}\right)^{-1} \in \mathcal{L}\left(\mathcal{B}_{2}, \mathcal{B}_{1}\right)$, so $x_{1}$ is well defined by the second substep of method (1.3) for $\mathrm{n}=0$ and (2.6). Furthermore, by (2.4), (2.8), (2.12) (for $\left.x=y_{0}\right)$, (2.14) (for $x=y_{0}$ ) and the estimate

$$
\begin{aligned}
x_{1}-p= & x_{0}-p-F^{\prime}\left(x_{0}\right)^{-1} F\left(x_{0}\right) \\
& -\frac{1}{2}\left[-3 I+\frac{9}{4} F^{\prime}\left(y_{0}\right)^{-1} F^{\prime}\left(x_{0}\right)\right. \\
& \left.+\frac{3}{4} F^{\prime}\left(x_{0}\right)^{-1} F^{\prime}\left(y_{0}\right)\right] F^{\prime}\left(x_{0}\right)^{-1} F\left(x_{0}\right) \\
= & x_{0}-p-F^{\prime}\left(x_{0}\right)^{-1} F\left(x_{0}\right) \\
& -\frac{3}{2}\left[-I+\frac{3}{4} F^{\prime}\left(y_{0}\right)^{-1} F^{\prime}\left(x_{0}\right)\right. \\
& \left.+\frac{1}{4} F^{\prime}\left(x_{0}\right)^{-1} F^{\prime}\left(y_{0}\right)\right] F^{\prime}\left(x_{0}\right)^{-1} F\left(x_{0}\right) \\
= & x_{0}-p-F^{\prime}\left(x_{0}\right)^{-1} F\left(x_{0}\right) \\
& -\frac{3}{8}\left[F^{\prime}\left(x_{0}\right)^{-1}\left(F^{\prime}\left(y_{0}\right)-F^{\prime}\left(x_{0}\right)\right) F^{\prime}\left(y_{0}\right)^{-1}\left(F^{\prime}\left(y_{0}\right)-F^{\prime}\left(x_{0}\right)\right)\right. \\
& -2 F^{\prime}\left(y_{0}\right)^{-1}\left(F^{\prime}\left(y_{0}\right)-F^{\prime}\left(x_{0}\right)\right] F^{\prime}\left(x_{0}\right)^{-1} F\left(x_{0}\right),
\end{aligned}
$$


we have in turn that

$$
\begin{aligned}
\left\|x_{1}-p\right\| \leq & \left\|x_{0}-p-F^{\prime}\left(x_{0}\right)^{-1} F\left(x_{0}\right)\right\| \\
& +\frac{3}{8}\left[\| F ^ { \prime } ( x _ { 0 } ) ^ { - 1 } F ^ { \prime } ( p ) \| \left(\left\|F^{\prime}(p)^{-1}\left(F^{\prime}\left(y_{0}\right)-F^{\prime}\left(x_{0}\right)\right)\right\|\right.\right. \\
& \left.+\left\|F^{\prime}(p)^{-1}\left(F^{\prime}\left(x_{0}\right)-F^{\prime}(p)\right)\right\|\right)^{2} \\
& \left\|F^{\prime}\left(y_{0}\right)^{-1} F^{\prime}(p)\right\| \\
& +2\left\|F^{\prime}\left(y_{0}\right)^{-1} F^{\prime}(p)\right\|\left(\| F^{\prime}(p)^{-1}\left(F^{\prime}\left(y_{0}\right)-F^{\prime}\left(x_{0}\right) \|\right.\right. \\
& \left.\left.+\left\|F^{\prime}(p)^{-1}\left(F^{\prime}\left(x_{0}\right)-F^{\prime}(p)\right)\right\|\right)\right] \\
& \left\|F^{\prime}\left(x_{0}\right)^{-1} F^{\prime}(p)\right\|\left\|F^{\prime}(p)^{-1} F\left(x_{0}\right)\right\| \\
\leq & \left\{\frac{\int_{0}^{1} \omega\left((1-\theta)\left\|x_{0}-p\right\|\right) d \theta}{1-\omega_{0}\left(\left\|x_{0}-p\right\|\right)}\right. \\
& \frac{3}{8}\left[\frac{\left(\omega_{0}\left(\left\|y_{0}-p\right\|\right)+\omega_{0}\left(\left\|x_{0}-p\right\|\right)\right)^{2}}{\left(1-\omega_{0}\left(\left\|x_{0}-p\right\|\right)\right)\left(1-\omega_{0}\left(\left\|y_{0}-p\right\|\right)\right)}\right. \\
& \left.+2 \frac{\omega_{0}\left(\left\|x_{0}-p\right\|\right)+\omega_{0}\left(\left\|y_{0}-p\right\|\right)}{1-\omega_{0}\left(\left\|y_{0}-p\right\|\right)}\right] \\
& \left.\frac{\int_{0}^{1} \omega_{1}\left(\theta\left\|x_{0}-p\right\|\right) d \theta}{1-\omega_{0}\left(\left\|x_{0}-p\right\|\right)}\right\}\left\|x_{0}-p\right\| \\
\leq & \varphi_{2}\left(\left\|x_{0}-p\right\|\right)\left\|x_{0}-p\right\| \leq\left\|x_{0}-p\right\|,
\end{aligned}
$$

so (2.10) holds for $n=0$ and $x_{1} \in U(p, R)$, where we also used the following estimates in the derivativation of (2.16):

$$
\begin{aligned}
& -I+\frac{3}{4} F^{\prime}\left(y_{0}\right)^{-1} F^{\prime}\left(x_{0}\right)+\frac{1}{4} F^{\prime}\left(x_{0}\right)^{-1} F^{\prime}\left(y_{0}\right) \\
= & -\frac{3}{4} I+\frac{3}{4} F^{\prime}\left(y_{n}\right)^{-1} F^{\prime}\left(x_{n}\right)-\frac{1}{4} I+\frac{1}{4} F^{\prime}\left(x_{0}\right)^{-1} F^{\prime}\left(y_{0}\right) \\
= & \frac{3}{4}\left[F^{\prime}\left(y_{0}\right)^{-1} F^{\prime}\left(x_{0}\right)-I\right]+\frac{1}{4}\left[F^{\prime}\left(x_{0}\right)^{-1} F^{\prime}\left(y_{0}\right)-I\right] \\
= & \frac{3}{4} F^{\prime}\left(y_{0}\right)^{-1}\left(F^{\prime}\left(x_{0}\right)-F^{\prime}\left(y_{0}\right)\right)+\frac{1}{4} F^{\prime}\left(x_{0}\right)^{-1}\left(F^{\prime}\left(y_{0}\right)-F^{\prime}\left(x_{0}\right)\right) \\
= & \frac{1}{4} F^{\prime}\left(x_{0}\right)^{-1}\left(F^{\prime}\left(y_{0}\right)-F^{\prime}\left(x_{0}\right)\right)-\frac{1}{4} F^{\prime}\left(y_{0}\right)^{-1}\left(F^{\prime}\left(y_{0}\right)-F^{\prime}\left(x_{0}\right)\right) \\
& -\frac{2}{4} F^{\prime}\left(y_{0}\right)^{-1}\left(F^{\prime}\left(y_{0}\right)-F^{\prime}\left(x_{0}\right)\right) \\
= & \frac{1}{4}\left(F^{\prime}\left(x_{0}\right)^{-1}-F^{\prime}\left(y_{0}\right)^{-1}\right)\left(F^{\prime}\left(y_{0}\right)-F^{\prime}\left(x_{0}\right)\right) \\
& -\frac{1}{2} F^{\prime}\left(y_{0}\right)^{-1}\left(F^{\prime}\left(y_{0}\right)-F^{\prime}\left(x_{0}\right)\right) \\
= & \frac{1}{4} F^{\prime}\left(x_{0}\right)^{-1}\left(F^{\prime}\left(y_{0}\right)-F^{\prime}\left(x_{0}\right)\right) F^{\prime}\left(y_{0}\right)^{-1}\left(F^{\prime}\left(y_{0}\right)-F^{\prime}\left(x_{0}\right)\right) \\
& -\frac{1}{2} F^{\prime}\left(y_{0}\right)^{-1}\left(F^{\prime}\left(y_{0}\right)-F^{\prime}\left(x_{0}\right)\right) .
\end{aligned}
$$


The induction for (2.9) and (2.10) is completed, if $x_{m}, y_{m}, x_{m+1}$ replace $x_{0}, y_{0}, x_{1}$ in the preceding estimations. Then, from the estimate

$$
\left\|x_{m+1}-p\right\| \leq r\left\|x_{m}-p\right\|<R, r=\varphi_{2}\left(\left\|x_{0}-p\right\|\right) \in[0,1)
$$

we conclude that $\lim _{m} \longrightarrow \infty x_{m}=p$ and $x_{m+1} \in U(p, R)$. Finally, let $G=\int_{0}^{1} F^{\prime}\left(p_{1}+\theta\left(p-p_{1}\right)\right) d \theta$ for $p_{1} \in \Omega_{1}$ with $F\left(p_{1}\right)=0$. Then, by (a2), we get that

$$
\begin{aligned}
\left\|F^{\prime}(p)^{-1}\left(G-F^{\prime}(p)\right)\right\| & \leq \int_{0}^{1} \omega_{0}\left(\theta\left\|p-p_{1}\right\|\right) d \theta \\
& \leq \int_{0}^{1} \omega_{0}\left(\theta R^{*}\right) d \theta<1
\end{aligned}
$$

leading to $\mathrm{G}^{-1} \in \mathcal{L}\left(\mathcal{B}_{2}, \mathcal{B}_{1}\right)$. Then, from the identity

$$
0=F(p)-F\left(p_{1}\right)=G\left(p-p_{1}\right)
$$

we deduce that $p_{1}=p$.

Next, we study the local convergence analysis of method (1.4) in an analogous way. Let $\omega_{0}, \omega, \omega_{1}, \rho_{0}, \varphi_{1}$ and $\bar{\varphi}_{1}$ are previously. Suppose that equation

$$
q(t)=1
$$

where $q(t)=\frac{1}{2}\left(3 \omega_{0}\left(\varphi_{1}(t) t\right)+\omega_{0}(t)\right)$ has at least one positive solution. Denote by $\rho_{1}$ the smallest such solution. Set $D_{1}=[0, \rho)$ where $\rho=\min \left\{\rho_{0}, \rho_{1}\right\}$. Define functions $\varphi_{3}$ and $\bar{\varphi}_{3}$ on $D_{1}$ by

$$
\begin{aligned}
\varphi_{3}(t)= & \frac{\int_{0}^{1} \omega((1-\theta) t) d \theta}{1-\omega_{0}(t)} \\
& +\frac{3}{2} \frac{\left(\omega_{0}(t)+\omega_{0}\left(\varphi_{1}(t) t\right)\right) \int_{0}^{1} \omega_{1}(\theta t) d \theta}{(1-q(t))\left(1-\omega_{0}(t)\right)}
\end{aligned}
$$

and

$$
\bar{\varphi}_{3}=\varphi_{3}-1
$$

We get $\bar{\varphi}_{3}(t)=-1$ and $\bar{\varphi}_{3}(t) \longrightarrow \infty$ as $t \longrightarrow \rho^{-}$. Denote by $R_{3}$ the smallest solution of equation $\bar{\varphi}_{3}=0$ in $(0, \rho)$. Define a radius of convergence $R$ by

$$
\mathrm{R}=\min \left\{\mathrm{R}_{1}, \mathrm{R}_{3}\right\}
$$

Consider the conditions (A) again but with $\mathrm{R}$ given in (2.23) and $\rho_{1}$ given in (2.22). Call these conditions $(A)^{\prime}$. Then, for each $t \in[0, R)$, we have

$$
\begin{gathered}
0 \leq \omega_{0}(t)<1 \\
0 \leq q(t)<1 \\
0 \leq \varphi_{1}(t)<1
\end{gathered}
$$

and

$$
0 \leq \varphi_{3}(\mathrm{t})<1
$$


Theorem 2.2. Suppose that the conditions (A) hold. Then, sequence $\left\{x_{n}\right\}$ defined by (1.4), starting at $\mathrm{x}_{0} \in \mathrm{U}(\mathrm{p}, \mathrm{R})-\{\mathrm{p}\}$ is well defined, remains in $\mathrm{U}(\mathrm{p}, \mathrm{R})$ for each $\mathrm{n}=0,1,2,3, \ldots$ and converges to $\mathrm{p}$. Moreover, the following error bounds hold

$$
\left\|y_{n}-p\right\| \leq \varphi_{1}(\|x-p\|)\|x-p\| \leq\|x-p\|<R
$$

and

$$
\left\|x_{n+1}-p\right\| \leq \varphi_{3}(\|x-p\|)\|x-p\| \leq\|x-p\|,
$$

where functions $\varphi_{1}$ and $\varphi_{3}$ are given previously and $\mathrm{R}$ is defined in (2.23). Furthermore, the limit point $\mathrm{p}$ is the only solution of equation $\mathrm{F}(\mathrm{x})=0$ in the set $\Omega_{1}$, which is defined previously.

Proof. It follows as in Theorem 2.1 but notice

$$
\begin{aligned}
& \left\|\left(2 F^{\prime}(p)\right)^{-1}\left(3 F^{\prime}\left(y_{0}\right)-F^{\prime}\left(x_{0}\right)-3 F^{\prime}(p)+F^{\prime}(p)\right)\right\| \\
\leq & \frac{1}{2}\left(3\left\|F^{\prime}(p)^{-1}\left(F^{\prime}\left(y_{0}\right)-F^{\prime}(p)\right)\right\|\right. \\
& \left.+\left\|F^{\prime}(p)^{-1}\left(F^{\prime}\left(x_{0}\right)-F^{\prime}(p)\right)\right\|\right) \\
\leq & \frac{1}{2}\left(3 \omega_{0}\left(\left\|y_{0}-p\right\|\right)+\omega_{0}\left(\left\|x_{0}-p\right\|\right)\right) \\
\leq & \frac{1}{2}\left(3 \omega_{0}\left(\varphi_{1}\left(\left\|x_{0}-p\right\|\right)\left\|x_{0}-p\right\|\right)+\omega_{0}\left(\left\|x_{0}-p\right\|\right)\right. \\
= & q\left(\left\|x_{0}-p\right\|\right)<1
\end{aligned}
$$

and

$$
\begin{aligned}
x_{1}-p= & x_{0}-p-\frac{1}{2}\left[\left(3 F^{\prime}\left(y_{0}\right)-F^{\prime}\left(x_{0}\right)\right)^{-1}\left(3 F^{\prime}\left(y_{0}\right)-F^{\prime}\left(x_{0}\right)\right)\right. \\
& \left.+2 F^{\prime}\left(x_{0}\right)\right] F^{\prime}\left(x_{0}\right)^{-1} F\left(x_{0}\right) \\
= & x_{0}-p-F^{\prime}\left(x_{0}\right)^{-1} F\left(x_{0}\right) \\
& -\frac{1}{2}\left[-I+2\left(3 F^{\prime}\left(y_{0}\right)-F^{\prime}\left(x_{0}\right)\right)^{-1}\right] F^{\prime}\left(x_{0}\right)^{-1} F\left(x_{0}\right) \\
= & x_{0}-p-F^{\prime}\left(x_{0}\right)^{-1} F\left(x_{0}\right)-\frac{3}{2}\left(3 F^{\prime}\left(y_{0}\right)-F^{\prime}\left(x_{0}\right)\right)^{-1} \\
& \times\left(F^{\prime}\left(x_{0}\right)-F^{\prime}\left(y_{0}\right)\right) F^{\prime}\left(x_{0}\right)^{-1} F\left(x_{0}\right),
\end{aligned}
$$

where for the derivation of (2.31), we also used the estimate

$$
\begin{aligned}
& -I+2\left(3 F^{\prime}\left(y_{0}\right)-F^{\prime}\left(x_{0}\right)\right)^{-1} F^{\prime}\left(x_{0}\right) \\
= & \left(3 F^{\prime}\left(y_{0}\right)-F^{\prime}\left(x_{0}\right)\right)^{-1}\left[-\left(3 F^{\prime}\left(y_{0}\right)-F^{\prime}\left(x_{0}\right)\right)+2 F^{\prime}\left(x_{0}\right)\right] \\
= & 3\left(3 F^{\prime}\left(y_{0}\right)-F^{\prime}\left(x_{0}\right)\right)^{-1}\left[F^{\prime}\left(x_{0}\right)-F^{\prime}\left(y_{0}\right)\right]
\end{aligned}
$$


so we get by (2.31)

$$
\begin{aligned}
\left\|x_{1}-p\right\| \leq & \left\|x_{0}-p-F^{\prime}\left(x_{0}\right)^{-1} F\left(x_{0}\right)\right\| \\
& +\frac{3}{2}\left\|\left(3 F^{\prime}\left(y_{0}\right)-F^{\prime}\left(x_{0}\right)\right)^{-1} F^{\prime}(p)\right\| \\
& \times\left[\left\|F^{\prime}(p)^{-1}\left(F^{\prime}\left(y_{0}\right)-F^{\prime}(p)\right)\right\|+\left\|F^{\prime}(p)^{-1}\left(F^{\prime}\left(x_{0}\right)-F^{\prime}(p)\right)\right\|\right] \\
& \times\left\|F^{\prime}\left(x_{0}\right)^{-1} F^{\prime}(p)\right\|\left\|F^{\prime}(p)^{-1} F(p)\right\| \\
\leq & {\left[\frac{\int_{0}^{1} \omega_{0}\left((1-\theta)\left\|x_{0}-p\right\|\right) d \theta}{1-\omega_{0}\left(\left\|x_{0}-p\right\|\right)}\right.} \\
& \left.+\frac{3}{2} \frac{\left(\omega_{0}\left(\left\|x_{0}-p\right\|\right)+\omega_{0}\left(\left\|y_{0}-p\right\|\right)\right) \int_{0}^{1} \omega_{1}\left(\theta\left\|x_{0}-p\right\|\right) d \theta}{\left(1-q\left(\left\|x_{0}-p\right\|\right)\right)\left(1-\omega_{0}\left(\left\|x_{0}-p\right\|\right)\right)}\right]\left\|x_{0}-p\right\| \\
\leq & \varphi_{3}\left(\left\|x_{0}-p\right\|\right)\left\|x_{0}-p\right\| \leq\left\|x_{0}-p\right\|<R,
\end{aligned}
$$

which shows (2.29) for $n=0$ and $x_{1} \in U(p, R)$. The rest of the proof as identical to the one in Theorem 2.1 is omitted.

Remark 2.3. (a) Let $\omega_{0}(\mathrm{t})=\mathrm{L}_{0} \mathrm{t}, \mathrm{\omega}(\mathrm{t})=\mathrm{Lt}$. Then, the radius $\mathrm{r}_{\mathrm{A}}=\frac{2}{2 \mathrm{~L}_{0}+\mathrm{L}}$ was obtained by Argyros in [4] as the convergence radius for Newton's method under condition (2.12)- 2.14). Notice that the convergence radius for Newton's method given independently by Rheinboldt [14] and Traub [16] is given by

$$
\rho=\frac{2}{3 \mathrm{~L}}<\mathrm{r}_{\mathrm{A}},
$$

where $\omega_{1}(\mathrm{t})=\mathrm{L}_{1} \mathrm{t}$ replaces $\omega(\mathrm{t})$, and $\mathrm{L}_{1}$ is the Lipschitz constant on $\Omega$. Notice that $\Omega_{0} \subseteq \Omega$, so $\mathrm{L}_{0} \leq \mathrm{L}_{1}$ and $\mathrm{L} \leq \mathrm{L}_{1}$. As an example, let us consider the function $\mathrm{f}(\mathrm{x})=\mathrm{e}^{\mathrm{x}}-1$. Then $\mathrm{p}=0$. Set $\mathrm{D}=\mathrm{U}(0,1)$. Then, we have that $\mathrm{L}_{0}=e-1<\mathrm{L}=e^{\frac{1}{e-1}}<\mathrm{L}_{1}=e$, so $\rho=0.24252961<r_{A}=0.3827$.

Moreover, the new error bounds [4, 5, 6, 7, 8] are:

$$
\left\|x_{n+1}-p\right\| \leq \frac{L}{1-L_{0}\left\|x_{n}-p\right\|}\left\|x_{n}-p\right\|^{2},
$$

whereas the old ones [10, 14, 16]

$$
\left\|x_{n+1}-p\right\| \leq \frac{L}{1-L\left\|x_{n}-p\right\|}\left\|x_{n}-p\right\|^{2} .
$$

Clearly, the new error bounds are more precise, if $\mathrm{L}_{0}<\mathrm{L}$. Then, the radius of convergence of method (1.3) or method (1.4) cannot be larger than $\mathrm{r}_{\mathrm{A}}$.

(b) The local results can be used for projection methods such as Arnoldi's method, the generalized minimum residual method(GMREM), the generalized conjugate method(GCM) for combined Newton/finite projection methods and in connection to the mesh independence principle in order to develop the cheapest and most efficient mesh refinement strategy [4, 5, 6, 7, 8, [10]. 
(c) The results can be also be used to solve equations where the operator $\mathrm{F}^{\prime}$ satisfies the autonomous differential equation [4, [5, 6, 7, [8, 10]:

$$
F^{\prime}(x)=p(F(x)),
$$

where $\mathrm{p}$ is a known continuous operator. Since $\mathrm{F}^{\prime}(\mathrm{p})=\mathrm{p}(\mathrm{F}(\mathrm{p}))=\mathrm{p}(0)$, we can apply the results without actually knowing the solution $\mathrm{p}$. Let as an example $\mathrm{F}(\mathrm{x})=\mathrm{e}^{\mathrm{x}}-1$. Then, we can choose $\mathrm{p}(\mathrm{x})=\mathrm{x}+1$ and $\mathrm{p}=0$.

(d) It is worth noticing that method (1.3) or method (1.4) are not changing, if we use the new instead of the old conditions [9, 12, 13]. Moreover, for the error bounds in practice we can use the computational order of convergence (COC)

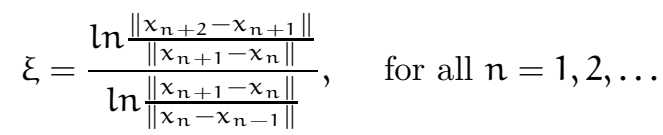

or the approximate computational order of convergence (ACOC)

$$
\xi^{*}=\frac{\ln \frac{\left\|x_{n+2}-p\right\|}{\left\|x_{n+1}-p\right\|}}{\ln \frac{\left\|x_{n+1}-p\right\|}{\left\|x_{n}-p\right\|}}, \quad \text { for all } n=0,1,2, \ldots
$$

instead of the error bounds obtained in Theorem 2.1. Notice that these formulae do not require high order derivatives and in the case of ACOC not even knowledge of $\mathrm{p}$. The convergence radii are optimum under conditions $(A)$.

(e) In view of (a2) and the estimate

$$
\begin{aligned}
\left\|F^{\prime}(p)^{-1} F^{\prime}(x)\right\| & =\left\|F^{\prime}(p)^{-1}\left(F^{\prime}(x)-F^{\prime}(p)\right)+I\right\| \\
& \leq 1+\left\|F^{\prime}(p)^{-1}\left(F^{\prime}(x)-F^{\prime}(p)\right)\right\| \leq 1+L_{0}\|x-p\|
\end{aligned}
$$

second condition in (a3) can be dropped and $\mathrm{M}$ can be replaced by

$$
M(t)=1+L_{0} t
$$

or

$$
M(t)=M=2,
$$

since $\mathrm{t} \in\left[0, \frac{1}{\mathrm{~L}_{0}}\right)$.

\section{Numerical examples}

Example 3.1. Let $\mathcal{B}_{1}=\mathcal{B}_{2}=\mathbb{R}^{3}, \Omega=\overline{\mathrm{U}}(0,1), x^{*}=(0,0,0)^{\top}$. Define function $\mathrm{F}$ on $\Omega$ for $u=(x, y, z)^{\top}$ by

$$
F(u)=\left(e^{x}-1, \frac{e-1}{2} y^{2}+y, z\right)^{\top} .
$$


Then, the Fréchet-derivative is given by

$$
F^{\prime}(v)=\left[\begin{array}{ccc}
e^{x} & 0 & 0 \\
0 & (e-1) y+1 & 0 \\
0 & 0 & 1
\end{array}\right] .
$$

Notice that using the (2.8)-(2.12), conditions, we get $\omega_{0}(t)=(e-1) t, \omega(t)=e^{\frac{1}{e-1}} t, \omega_{1}(t)=e^{\frac{1}{e-1}}$.

Then using the definition of $\mathrm{r}$, we have that

$\mathrm{R}_{1}=0.15440695135715407082521721804369=\mathrm{R}$

and

$\mathrm{R}_{2}=0.17352535186531112265662102345232$.

Example 3.2. Let $\mathcal{B}_{1}=\mathcal{B}_{2}=\mathrm{C}[0,1]$, the space of continuous functions defined on $[0,1]$ and be equipped with the max norm. Let $\Omega=\overline{\mathrm{U}}(0,1)$. Define function $\mathrm{F}$ on $\Omega$ by

$$
\mathrm{F}(\varphi)(x)=\varphi(x)-5 \int_{0}^{1} x \theta \varphi(\theta)^{3} \mathrm{~d} \theta
$$

We have that

$$
F^{\prime}(\varphi(\xi))(x)=\xi(x)-15 \int_{0}^{1} x \theta \varphi(\theta)^{2} \xi(\theta) d \theta, \text { for each } \xi \in \Omega .
$$

Then, we get that $\mathrm{x}^{*}=0, \omega_{0}(\mathrm{t})=7.5 \mathrm{t}, \omega(\mathrm{t})=15 \mathrm{t}, \mathrm{\omega}_{1}(\mathrm{t})=2$. This way, we have that

$\mathrm{R}_{1}=0.022222222222222222222222222222222=\mathrm{R}$

and

$\mathrm{R}_{2}=0.18929637111931424398036938328005$.

Example 3.3. Let $\mathcal{B}_{1}=\mathcal{B}_{2}=\mathbb{R}, \Omega=\left[-\frac{1}{2}, \frac{3}{2}\right]$. Define $\mathrm{F}$ on $\Omega$ by

$$
\mathrm{F}(\mathrm{x})=\mathrm{x}^{3} \log \mathrm{x}^{2}+x^{5}-\mathrm{x}^{4}
$$

Then

$$
F^{\prime}(x)=3 x^{2} \log x^{2}+5 x^{4}-4 x^{3}+2 x^{2}
$$

Then, we get that $\omega_{0}(t)=\omega(t)=147 t, \omega_{1}(t)=2$. So, we obtain

$\mathrm{R}_{1}=0.0015117157974300831443688586545729=\mathrm{R}$

and

$\mathrm{R}_{2}=0.01297295712377562193484692443235$.

Example 3.4. Let $\mathcal{B}_{1}=\mathcal{B}_{2}=\mathrm{C}[0,1], \Omega=\overline{\mathrm{U}}\left(x^{*}, 1\right)$ and consider the nonlinear integral equation of the mixed Hammerstein-type [1, 2, 3, 5, 11] defined by

$$
x(s)=\int_{0}^{1} G(s, t)\left(x(t)^{3 / 2}+\frac{x(t)^{2}}{2}\right) d t
$$


where the kernel $\mathrm{G}$ is the Green's function defined on the interval $[0,1] \times[0,1]$ by

$$
G(s, t)= \begin{cases}(1-s) t, & t \leq s \\ s(1-t), & s \leq t\end{cases}
$$

The solution $\mathrm{x}^{*}(\mathrm{~s})=0$ is the same as the solution of equation (1.1), where $\left.\mathrm{F}: \mathrm{C}[0,1] \longrightarrow \mathrm{C}[0,1]\right)$ is defined by

$$
F(x)(s)=x(s)-\int_{0}^{1} G(s, t)\left(x(t)^{3 / 2}+\frac{x(t)^{2}}{2}\right) d t .
$$

Notice that

$$
\left\|\int_{0}^{1} G(s, t) d t\right\| \leq \frac{1}{8}
$$

Then, we have that

$$
F^{\prime}(x) y(s)=y(s)-\int_{0}^{1} G(s, t)\left(\frac{3}{2} x(t)^{1 / 2}+x(t)\right) d t,
$$

so since $\mathrm{F}^{\prime}\left(\mathrm{x}^{*}(\mathrm{~s})\right)=\mathrm{I}$,

$$
\left\|F^{\prime}\left(x^{*}\right)^{-1}\left(F^{\prime}(x)-F^{\prime}(y)\right)\right\| \leq \frac{1}{8}\left(\frac{3}{2}\|x-y\|^{1 / 2}+\|x-y\|\right) .
$$

Then, we get that $\omega_{0}(t)=\omega(t)=\frac{1}{8}\left(\frac{3}{2} t^{1 / 2}+t\right), \omega_{1}(t)=1+\omega_{0}(t)$. So, we obtain $\mathrm{R}_{1}=1.2$

and

$\mathrm{R}_{2}=0.82757632634917221992054692236707=\mathrm{R}$. 


\section{References}

[1] Amat, S., Busquier, S., Plaza, S., On two families of high order Newton type methods, Appl. Math. Comput., 25, (2012), 2209-2217.

[2] Amat, S., Argyros, I. K., Busquier, S., Hernandez, M. A., On two high-order families of frozen Newton-type methods, Numer., Lin., Alg. Appl., 25 (2018), 1-13.

[3] Argyros, I.K., Ezquerro, J. A., Gutierrez, J. M., Hernandez, M. A., Hilout, S., On the semilocal convergence of efficient Chebyshev-Secant-type methods, J. Comput. Appl. Math., 235, (2011), 3195-2206.

[4] Argyros, I. K., George, S., Thapa, N., Mathematical Modeling For The Solution Of Equations And Systems Of Equations With Applications, Volume-I, Nova Publishes, NY, 2018.

[5] Argyros, I. K., George, S., Thapa, N., Mathematical Modeling For The Solution Of Equations And Systems Of Equations With Applications, Volume-II, Nova Publishes, NY, 2018.

[6] I.K.Argyros and S. Hilout Weaker conditions for the convergence of Newton's method, J. Complexity, 28, (2012), 364-387.

[7] Argyros, I. K, Magréñan, A. A, A contemporary study of iterative methods, Elsevier (Academic Press), New York, 2018.

[8] Argyros, I.K., Magreñán, A.A., Iterative methods and their dynamics with applications, CRC Press, New York, USA, 2017.

[9] Cordero,A., Hueso, J. L., Martinez, E., Torregrosa, J. R., A modified Newton-Jarratt's composition, Numer. Algorithms, 55, (2010), 87-99.

[10] Kantorovich, L.V., Akilov, G.P., Functional analysis in normed spaces, Pergamon Press, New York, 1982.

[11] Hernandez, M. A., Martinez, E., Tervel, C., Semi-local convergence of a k-step iterative process and its application for solving a special kind of conservative problems, Numer. Algor. , 76, (2017), 309-331.

[12] Jarratt, P., Some fourth order multipoint iterative methods for solving equations, Math. Comput., 20, (1966), 434-437.

[13] Petkovic, M.S., Neta, B., Petkovic, L., Džunič, J., Multipoint methods for solving nonlinear equations, Elsevier, 2013.

[14] Rheinboldt, W.C., An adaptive continuation process for solving systems of nonlinear equations, Polish Academy of Science, Banach Ctr. Publ. 3 (1978), no. 1, 129-142. 
[15] Sharma, J.R., Guha, R. K., Sharma, R., An efficient fourth order weighted Newton method for systems of nonlinear equations, Numer. Algorithm, 62 (2013), 307-323.

[16] J.F. Traub, Iterative methods for the solution of equations, Prentice- Hall Series in Automatic Computation, Englewood Cliffs, N. J., 1964. 